\title{
The Influence of Parents Feeding Practices, Eating Knowledge, and Attitude on Eating Behavior among Senior High School Students in South Tangerang, Indonesia
}

\author{
Siti Soraya ${ }^{1 *(\mathbb{D})}$, Dwi Hastuti ${ }^{(\mathbb{D})}$, Irni Johan $^{2}$ (i) \\ ${ }^{1}$ Study Program of Magister Sciences of Family and Child Development, IPB University, Bogor 16680, Indonesia; ${ }^{2}$ Department \\ of Family and Consumer Sciences, Faculty of Human Ecology, IPB University, Bogor 16680, Indonesia
}

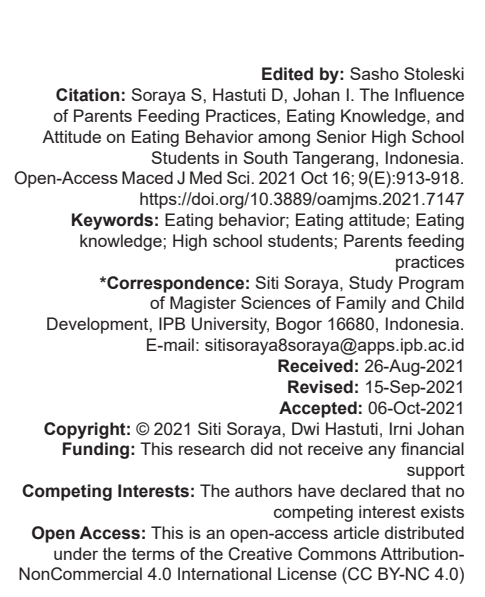

\section{Abstract}

BACKGROUND: Adolescence is a period of transition from childhood to early adulthood, an important period because of the rapid development of reproductive organs. The quality of adolescent food consumption in South Tangerang City in 2018 was not appropriate because of consumption less fiber, fruit, and vegetables, consuming foods high in sugar, fast food, and skipping meals, and consuming snacks outside the home. Adolescent eating behavior was also determined through knowledge information and attitude about food originated from parents feeding practices that influenced adolescent eating behavior.

AIM: This study aims to determine the effect of parents' feeding practices, eating knowledge, and attitude on eating behavior among senior high school students in South Tangerang.

METHODS: The study involved 503 high school students who were selected purposively using the online data collection through convenience sampling technique. The design of this study used a cross-sectional study through an online self-administered method with the help of a questionnaire. Path analysis is used to see the direct and indirect effects using the Statistical Package for the Social Sciences 25.0.

RESULTS: The influence test results show that parents feeding practices $\left({ }_{\mathrm{px} 1}=0.318^{*}\right)$, eating knowledge $\left(_{\mathrm{PX} 2}=0.158^{*}\right)$, and eating attitudes $\left({ }_{\mathrm{PX} 3}={ }^{*} 0.022\right)$ directly affect students eating behavior.

CONCLUSION: There was a significant effect of parents' feeding practices, knowledge, and eating attitude on the eating behavior.

\section{Introduction}

Adolescence is an important stage of human development. An adolescent will experience many psychological and social changes influenced by the interaction with the social environment in shaping individual abilities in adult life [1]. According to the World Health Organization in 2019, the psychological changes experienced by adolescents through adopting a healthy lifestyle such as getting used to consuming home-cooked food provided by their parents and not consuming fast food processed food because they contribute to an increase in overweight and noncommunicable diseases [2].

The Central Bureau of Statistics Republic of Indonesia in 2017 explained, as living beings, humans cannot be separated from food which is a basic need, therefore, diet is the most important behavior that can affect nutritional status [3]. The Ministry of Health of the Republic of Indonesia in 2005 reported the eating behavior of adolescents tends to skip breakfast (65.2\%), consumes less fiber and fruit vegetables (93.6\%), and often consumes foods high in sodium that is fast food and junk food (75.7\%) [4]. Parents feeding practices are applied to children related to feeding. The home and family environment play an important role in the frequency of eating for adolescents, therefore, adolescents who have a regular meal frequency, the presence of parents at mealtimes have good benefits for the quality of healthy eating. Other studies have shown that parents feeding practices have a significant effect on eating behavior and food quality, therefore, the influence of parents feeding practices with the presence and involvement of parents in daily routines affects adolescent eating behavior [5], [6].

Irregular eating behavior harms adolescent health [7]. An unhealthy lifestyle in adolescents by skipping breakfast, frequently consuming snacks, and not consuming fruits and vegetables are factors of being overweight [8]. Many factors make adolescents skip breakfast, namely, the lack of parental presence is associated with the risk of skipping breakfast and parents do not apply feeding practices such as implementing positive eating habits at home [9]. Adolescence is a stage of body development, at this time, many adolescence experience eating disorders because anxiety about weight gain is one of the risk 
factors for experiencing anorexia and bulimia (bulimia nervosa and bulimic eating).

Eating behavior in adolescents is influenced by internal and external factors. Internal factors consist of knowledge and eating attitudes, external factors that influence eating behavior are parents' feeding practices. Research on parents' feeding practices, knowledge, eating attitudes, and eating behavior of adolescents has been carried out with the subject of preschool children, therefore, the novelty of this research is the application of parents' feeding practices that play an important role in adolescents.

Table 1: Distribution of respondents by category of parents' feeding practices

\begin{tabular}{|c|c|}
\hline \multirow[t]{2}{*}{ Parents' feeding practices } & \multirow{2}{*}{$\begin{array}{l}(\mathrm{n}=503) \\
\text { Percentage }\end{array}$} \\
\hline & \\
\hline \multicolumn{2}{|c|}{ Encouragement of parents to eat healthy } \\
\hline High & 0.2 \\
\hline Moderate & 11.3 \\
\hline Low & 88.5 \\
\hline Min-max & $4-20$ \\
\hline Mean \pm Std (index) & $36.09 \pm 14.12$ \\
\hline \multicolumn{2}{|l|}{ Negotiation } \\
\hline High & 7.8 \\
\hline Moderate & 33.2 \\
\hline Low & 59.0 \\
\hline Min-max & $4-16$ \\
\hline Mean \pm Std (index) & $50.05 \pm 19.61$ \\
\hline \multicolumn{2}{|c|}{ Pressure to consume foods they do not like } \\
\hline High & 5.0 \\
\hline Moderate & 9.7 \\
\hline Low & 85.3 \\
\hline Min-max & $3-12$ \\
\hline Mean \pm Std (index) & $25 \pm 24.0$ \\
\hline \multicolumn{2}{|c|}{ Pressure to eat food when not hungry } \\
\hline High & 8.9 \\
\hline Moderate & 21.9 \\
\hline Low & 69.2 \\
\hline Min-max & $3-12$ \\
\hline Mean \pm Std (index) & $39 \pm 23.2$ \\
\hline \multicolumn{2}{|l|}{ Monitoring } \\
\hline High & 1.0 \\
\hline Moderate & 14.9 \\
\hline Low & 84.1 \\
\hline Min-max & $10-40$ \\
\hline Mean \pm Std (index) & $39.86 \pm 12.13$ \\
\hline \multicolumn{2}{|l|}{ Parents' feeding practices } \\
\hline High & 0.8 \\
\hline Moderate & 15.5 \\
\hline Low & 83.7 \\
\hline Min-max & $25-96$ \\
\hline Mean \pm Std (index) & $39.38 \pm 11.18$ \\
\hline
\end{tabular}

Table 2: Distribution of respondents by category of eating knowledge

\begin{tabular}{ll}
\hline Eating knowledge & $(\mathrm{n}=503)$ \\
\cline { 2 - 2 } Percentage & \\
High ring recommendation & 7.6 \\
Moderate & 40.2 \\
Low & 52.3 \\
Min-max & $0-7$ \\
Mean \pm Std (index) & $48.82 \pm 20.70$ \\
Food source & \\
High & 11.7 \\
Moderate & 35.8 \\
Low & 52.5 \\
Min-max & $1-5$ \\
Mean \pm Std (index) & $59.15 \pm 25.36$ \\
Food choice & \\
High & 14.9 \\
Moderate & 49.3 \\
Low & 35.8 \\
Min-max & $1-8$ \\
Mean \pm Std (index) & $53.70 \pm 57.14$ \\
Eating knowledge & \\
High & 14.9 \\
Moderate & 49.3 \\
Low & 35.8 \\
Min-max & $2-18$ \\
Mean \pm Std (index) & $59.64 \pm 17.7$ \\
\hline Low (<60), moderate (60-80), and high (>80). & \\
& \\
\hline
\end{tabular}

Based on the explanation above, parents' feeding practices, knowledge, eating attitudes, and eating behavior of adolescents need to be investigated because the family environment strongly influences adolescent eating behavior. In general, this study aims to determine the effect of parents' feeding practices, knowledge, and eating attitudes on adolescent eating behavior. The Ministry of Health of the Republic of Indonesia in 2018 shows that adolescents in the city of South Tangerang are at risk of consuming foods high in sugar, salt, and fat and this is a risk factor for obesity among adolescents, therefore, obesity in adolescents

Table 3: Distribution of respondents by category of eating attitude

\begin{tabular}{ll}
\hline Eating attitude & $(\mathrm{n}=503)$ \\
\cline { 2 - 2 } & Percentage \\
\hline Caring about nutrition & 9.5 \\
High & 32.4 \\
Moderate & 58.1 \\
Low & $0.00-100$ \\
Min-max & $49.88 \pm 17.77$ \\
Mean \pm Std (index) & \\
Consuming new foods & 15.7 \\
High & 65.8 \\
Moderate & 58.4 \\
Low & $12.50-100$ \\
Min-max & $65.92 \pm 15.03$ \\
Mean \pm Std (index) & \\
Nutrition affecting health & 58.4 \\
High & 38.6 \\
Moderate & 3.0 \\
Low & $25.0-100$ \\
Min-max & $81.94 \pm 12.21$ \\
Mean \pm Std (index) & \\
Nutrition learning & 20.5 \\
High & 60 \\
Moderate & 19.5 \\
Low & $0.00-100$ \\
Min-max & $66.81 \pm 16.47$ \\
Mean \pm Std (index) & \\
Eating attitude & 11.7 \\
High & 77.5 \\
Moderate & 10.7 \\
Low & $32-96$ \\
Min-max & $63.24 \pm 10.94$ \\
Mean \pm Std (index) & \\
\hline Low (<60), moderate (60-80), and high (>80). &
\end{tabular}

Table 4: Distribution of respondents by category of students eating behavior

\begin{tabular}{ll}
\hline Adolescent eating behavior & $(\mathrm{n}=503)$ \\
\cline { 2 - 2 } & Percentage \\
\hline Eating schedule & \\
High & 11.5 \\
Moderate & 46.6 \\
Low & 41.9 \\
Min-max & $8.33-100$ \\
Mean \pm Std (index) & $56.51 \pm 17.78$ \\
Type of food & \\
High & 3.20 \\
Moderate & 61.4 \\
Low & 35.4 \\
Min-max & $24.24-84.84$ \\
Mean \pm Std (index) & $54.32 \pm 10.07$ \\
Amount of food & 27.2 \\
High & 37.2 \\
Moderate & 35.6 \\
Low & $0.00-100$ \\
Min-max & $64.21 \pm 17.71$ \\
Mean \pm Std (index) & \\
Eating disorder & 1.0 \\
High & 12.9 \\
Moderate & 86.1 \\
Low & $0.00-100$ \\
Min-max & $28.45 \pm 17.93$ \\
Mean \pm Std (index) & \\
Eating behavior & 0.4 \\
High & 54.3 \\
Moderate & 45.3 \\
Low & $30-76$ \\
Min-max & $51.86 \pm 8.70$ \\
Mean \pm Std (index) & \\
\hline Low (<60), moderate (60-80), and high (>80). & \\
& \\
\hline
\end{tabular}


Table 5: The influence of direct, indirect, and total influence of exogenous variables in endogenous variables (students of eating behavior)

\begin{tabular}{|c|c|c|c|}
\hline Variable & Direct & Indirect & Total Effect \\
\hline$X$ to $Y$ & & $X_{1}$ through $X_{2}$ to $Y$ & \\
\hline $\begin{array}{l}\text { Parents' feeding practices } \\
X_{2} \text { to } Y\end{array}$ & $0.318^{*}$ & $\begin{array}{l}-0,076 \times 0.158^{*}=-0.0120 \\
X_{\text {, through }} \mathrm{X}_{\text {s }} \text { to } \mathrm{Y}\end{array}$ & 0.306 \\
\hline $\begin{array}{l}\text { Eating knowledge } \\
X_{3} \text { to } Y\end{array}$ & $0.158^{*}$ & $0.146^{*} \times 0.022^{*}=0.003$ & 0.161 \\
\hline Eating attitudes & $0.022^{*}$ & & 0.022 \\
\hline
\end{tabular}

aged $\geq 15$ years in the city of South Tangerang, Banten Province by $11.78 \%$ [10].

\section{Methods}

The research conducted had passed the ethical review from the Human Research Ethics Committee of the Bogor Agricultural University with the number: 338/ IT3.KEPMSM-IPB/SK/2021 on February 1, 2021.The design of this study used a cross-sectional study with a population of all students from senior high schools in South Tangerang City from January to March 2021. Furthermore, the measuring instrument is filled in using a self-administered online method with a questionnaire. The research population was high school students consisting of six schools in the South Tangerang City area with a total of 503 respondents. Sampling was done by purposive sampling method with convenience sampling technique, namely, students who filled out the online questionnaire were students who were willing to provide information.

\section{Sociodemographic characteristics}

The sociogeographical characteristics data collected in this study were primary data using an online questionnaire, including students characteristics (gender, age, and pocket money), family characteristics (parental education and parental income), parents feeding practices, knowledge, attitudes, and eating behavior of students.

\section{Parent's feeding practices}

The measurement of parent's feeding practices is referred to from Adolescent Perception of Parent's Feeding Practices by Birch (2001) [11]. The value of Cronbach's alpha questionnaire on parent's feeding practices is 0.725 .

\section{Eating attitudes}

The nutrition attitude scales refer to measurement of eating attitudes by Byrd-Bredbenner (1984) [12]. The value of Cronbach's alpha questionnaire attitude to eating is 0.736 .

\section{Eating knowledge}

Measuring knowledge of eating is referred to from the general nutrition knowledge questionnaire by Parmenter et al. (2000) [13]. The value of Cronbach's alpha eating knowledge questionnaire is 0.661 .

\section{Eating behavior}

The measurement of students eating behavior was modified and referred to from Block's Screening Scales by Block (1989) [14]. The value of Cronbach's alpha on the adolescent eating behavior questionnaire is 0.687 .

\section{Data analysis}

Data analysis using descriptive and inferential analysis used to answer the research objectives, namely: Descriptive statistical analysis was conducted to see the distribution of frequency, average, standard deviation, minimum value, and maximum value on students characteristics, family characteristics, parents' feeding practices, knowledge, attitudes, and eating behavior; correlation analysis is used to determine the relationship between variables which include students characteristics (age, gender, and pocket money), family characteristics (parental education, parental income, parents' feeding practices, knowledge, and eating attitudes with students eating behavior; path analysis test using the Statistical Package for the Social Sciences to determine variables that directly and indirectly affect adolescent eating behavior. The results of this study were categorized using the cutoff point categorization, namely, low $(<50)$, moderate (50.175.0), and high (>75.1)

\section{Results}

\section{Characteristics of students and families}

This study involved 503 students, consisting of 167 boys (33.2\%) and 336 girls (66.8\%). The age range of students who took part in this study was 15-18 years old with an average age of 16 years, namely, 176 people (35.0\%), 17 years old 147 people (29.2\%), 18 years old 59 people $(11.7 \%)$, and the youngest age who participated in this study were 15 years $(24.1 \%)$. The students have maximum pocket money of Rp. 100.000 and minimum pocket money of Rp. 0 . Students get an average of Rp. 23.123.

Most father's was graduated from completed the university education (59.4\%), and most mother's was graduated from completed the university education $(50.9 \%)$. In this research, parents have a maximum monthly income of Rp. 5.000 .000 and a minimum of 
Rp. 0. Furthermore, judging from the level of income in South Tangerang City, the respondent's parents fall into the capable category because their income is included in the minimum South Tangerang city of Rp. 4.200.000 per month.

\section{Parents' feeding practices}

The parents' feeding practices in this study consist of five dimensions, namely, the encouragement of parents to eat healthy, negotiation, pressure to consume foods they do not like, pressure to eat food when not hungry, and monitoring. The average result of the parents' feeding practices index is 39.38 which is in the low category. In addition, the average index of adolescent parents' feeding practices based on the dimensions of encouragement to eat healthily was 36.09 in the low category, the average negotiation index was 50.05 in the medium category, the average pressure index to consume foods that were not liked was 25 in the low category, the average pressure index to consuming food when not hungry 39 in the low category, and the average monitoring index 39.86 in the low category (Table 1).

\section{Eating knowledge}

Based on the average index score of students eating knowledge as a whole is $\mathbf{5 9 . 6 4}$ in the moderate category. The results of this study indicate that based on the eating knowledge dimension, the average index on the eating recommendation dimension is 48.82 in the low category, the average food source index is 59.15 in the moderate category, and the average food choice index is 53.70 in the moderate category (Table 2).

\section{Eating attitude}

The eating attitude in this study consisted of four dimensions to measure their perception whether agree or disagree toward nutrition issues and learning, namely, caring about nutrition, consuming new foods, nutrition affecting health, and learning about nutrition. The results of this study indicate that the overall eating attitude index score is 63.24 in the moderate category, then the average index on the nutrition care dimension is 49.88 with the low category, the average index of consuming new foods is 65.92 in the moderate category, the average nutritional index affect health is 81.94 in the high category, and the average index of nutrition learning is 66.81 in the medium category (Table 3 ).

\section{Students eating behavior}

Students eating behavior consists of four dimensions to measure practice on eating, namely, the amount, and type of food, eating schedule, and eating disorders. The results of this study indicate that the overall average score of the eating behavior index of students is 51.86 in the moderate category, then the average index of students eating behavior on the eating schedule dimension is 56.51 , the type of eating is 54.32 , the number of meals is 64.21 , then, all three are in the moderate category, and the average eating disorder index is 28.45 in the low category (Table 4).

\section{Factors that influence students eating behavior}

Variables that have a direct or indirect influence on students eating behavior are described by path analysis in Figure 1. Students eating behavior is directly influenced by parents' feeding practices $\left(P X 1=0.318^{*}\right)$, eating knowledge $\left(\mathrm{PX} 2=0.158^{*}\right)$, and eating attitude $\left(\mathrm{PX} 3=0.022^{*}\right)($ Table 5$)$.

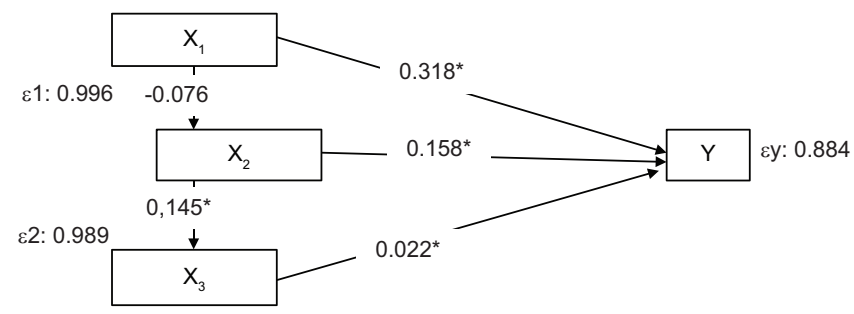

Figure 1: Path analysis

Description

$Y=$ Students eating behavior, $X 1=$ Parents' feeding practices, $X 2=$ Eating knowledge, $X 3=$ Eating attitude, $\varepsilon^{1}=$ Path coefficient $X 1$ to $X 2, \varepsilon 2=$ Coefficient path $X 2$ to $X 3, \varepsilon y=$ Path coefficient $y$

Parents' feeding practices directly affect students eating behavior (PX1Y), eating knowledge indirectly affects students eating behavior through eating attitude (PX2X3), and eating attitude directly affects students eating behavior (PX3Y).

\section{Discussion}

The results showed that the parents' feeding practice of students was categorized as low. The low feeding practice is due to the restrictions on eating by parents for children and this affects adolescents' decision-making on the food they choose [15]. In the previous studies, parents' feeding practice is related to eating attitudes and eating behavior of students because parents who form parents' feeding practice patterns in the home environment will make children have experience with what they will consume, this experience will shape children's attitudes in determining their eating because of eating attitudes. A good diet will have a major effect on adolescent eating behavior in the future [16].

This study shows the factors that influence eating behavior directly or indirectly. Parents feeding 
practices, knowledge, and eating attitudes directly have a significant and positive effect on adolescent eating behavior $(0.000<0.05)$, as well as research conducted by Nurfitriliani in 2019 which states that the higher the parent's feeding practice, the higher the eating behavior of adolescents. The parents feeding practices food positively accompanied by warm open communication between parents and children that could increase healthy eating behavior [17].

This study indicates that parents' feeding practices have a significant indirect effect through eating knowledge on students' eating behavior. Positive parents' feeding practices applied by mothers are associated with high knowledge of eating among respondents because the creation of a healthy home environment is associated with a lack of adolescent consumption of fast food and better adolescent eating knowledge [18].

Knowledge of eating in this study has a significant effect on eating attitudes $(0.000<0.5)$, this is in line with other's findings which showed that eating behavior is influenced by many factors including eating knowledge and eating attitudes [19]. A child has a low eating attitude due to the lack of parents preparing food and their low knowledge of eating, this group of adolescents is responsible for themselves for their eating behavior which will affect long-term health. The results show that adolescents have limited nutritional knowledge, and good eating attitudes have an influence on food choices compared to nutritional knowledge because high nutritional knowledge is associated with one's beliefs [20].

The results of this study indicate that parents' feeding practice does not affect eating knowledge. Parents' feeding practices directly affect children's eating behavior, such as controlling the availability and accessibility of food at home and modeling eating behavior to children [21].

\section{Conclusion}

The results showed that parents' feeding practices are at an average index of 39.38 (low), eating knowledge is at an average index of 59.64 (moderate), eating attitudes are at an average index of 63,24 (moderate), and students eating behavior is at an average index of 51,86 (moderate).

The results state that parents' feeding practices, knowledge, and eating attitudes directly affect students' eating behavior. However, parents' feeding practices have no direct significant effect on eating knowledge, then eating knowledge directly has a significant effect on eating attitudes and indirectly, significant eating knowledge through eating attitudes on students eating behavior.

\section{References}

1. Wu XY, Zhuang LH, Li W, Guo HW, Zhang JH, Zhao YK, et al The influence of diet quality and dietary behavior on healthrelated quality of life in the general population of children and adolescents: A systematic review and meta-analysis. Qual Life Res. 2019;28(8):1989-2015. https://doi.org/10.1007/ s11136-019-02162-4

PMid:30875010

2. World Health Organization. Interpretation Guide. Nutrition Landscape Information System (NLIS) Country Profile. Geneva: World Health Organization; 2010. p. 50. Available from: http:// www.who.int/nutrition. [Last accessed on 2021 Mar 16].

3. Statistik BP. Survey Sosial Ekonomi Nasional (SUSENAS) Maret 2017. Jakarta: Badan Pusat Statistik; 2017.

4. Sadar K, Kadarzi G, Menuju D, Baik G, Semua U. Family aware of nutrition (kadarzi) towards good nutrition for all. Abas Basuni Jahari. 2005;28(1):1-8. https://doi.org/10.36457/gizindo. v28i1.12

5. Kitzman-Ulrich H, Wilson DK, St. George SM, Segal M, Schneider E, Kugler K. A preliminary test of a motivational and parenting weight loss program targeting low-income and minority adolescents. Child Obes. 2011;7(5):379-84. https://doi. org/10.1089/chi.2011.0030

6. Loth KA, MacLehose RF, Fulkerson JA, Crow $S$ Neumark- Sztainer D. Eat this, not that! Parental demographic correlates of food-related parenting practices. Appetite. 2013;60(1):140-7. https://doi.org/10.1016/j.appet.2012.09.019 PMid:23022556

7. Eaton DK, Kann L, Kinchen S, Ross J, Hawkins J, Harris WA, et al. Youth risk behavior surveillance-United States, 2005. J Sch Health. 2006;76(7):353-72. https://doi. org/10.1111/j.1746-1561.2006.00127.x PMid: 16918870

8. Snoek HM, van Strien T, Janssens JM, Engels RC. Emotional, external, restrained eating and overweight in Dutch adolescents. Scand J Psychol. 2007;48(1):23-32. https://doi. org/10.1111/j.1467-9450.2006.00568.x

PMid:17257366

9. Yang RJ, Wang EK, Hsieh YS, Chen MY. Irregular breakfasteating and health status among adolescents in Taiwan. BMC Public Health. 2006;6:295. https://doi.org/10.1186/1471-2458-6-295 PMid:17150112

10. Riskesdas K. Hasil utama riset kesehata dasar (RISKESDAS). J Phys A Math Theor. 2018;44(8):1-200. Available from: https:// kesmas.kemkes.go.id/assets/upload/dir_519d41d8cd98f00/ files/Hasil-riskesdas-2018_1274.pdf

11. MacFarlane A, Crawford D, Worsley A. Associations between parental concern for adolescent weight and the home food environment and dietary intake. J Nutr Educ Behav. 2010;42(3):152-60. http://dx.doi.org/10.1016/j.jneb.2008.11.004 PMid:20097613

12. Byrd-Bredbenner C, O'Connell LH, Shannon B, Eddy JM. A nutrition curriculum for health education: Its effect on students' knowledge, attitude, and behavior. J Sch Health. 1984;54(10):385-8. https://doi.org/10.1111/j.1746-1561.1984. tb08885. $x$ 


\section{PMid:6569273}

13. Parmenter K, Waller J, Wardle J. Demographic variation in nutrition knowledge in England. Health Educ Res. 2000;15(2):163-74. https://doi.org/10.1093/her/15.2.163 PMid: 10751375

14. Block G, Clifford C, Naughton MD, Henderson M, McAdams M. A brief dietary screen for high fat intake. J Nutr Educ. 1989;21(5):199-207. https://doi. org/10.1016/ s0022-3182(89)80003-2

15. Faith MS, Scanlon KS, Birch LL, Francis LA, Sherry B. Parent- child feeding strategies and their relationships to child eating and weight status. Obes Res. 2004;12(11):1711-22. https://doi.org/10.1038/oby.2004.212

PMid:15601964

16. Zarnowiecki D, Sinn N, Petkov J, Dollman J. Parental nutrition knowledge and attitudes as predictors of 5-6-year-old children's healthy food knowledge. Public Health Nutr. 2012;15(7):1284-90. https://doi.org/10.1017/ s1368980011003259

PMid:22166312
17. Baumrind $D$. The influence of parenting style on adolescent competence and substance use. J Early Adolesc. 1991;11:56-95. https://doi.org/10.1177/0272431691111004

18. Ferris KA, Babskie E, Metzger A. Associations between foodrelated parenting behaviors and adolescents' engagement in unhealthy eating behaviors. Int $\mathrm{J}$ Aging Hum Dev. 2017;84(3):231-46. https://doi.org/10.1177/0091415016685325 PMid:28033713

19. Armitage CJ, Christian J. From attitudes to behavior: Basic and applied research on the theory of planned behavior. Plan Behav. 2017;22(3):1-12.

20. Goering C. Amnesty International and Economic, Social, and Cultural Rights. The Ethical Challenges of International Human Rights; 2007. p. 204.

21. Nicklas TA, Baranowski T, Cullen KW, Berenson G. Eating patterns, dietary quality and obesity. J Am Coll Nutr. 2001;20(6):599-608. https://doi.org/10.1080/07315724.2001.10 719064

PMid:11771675 